\title{
Appendiceal Carcinoma pT4a TNM Finding v8
}

National Cancer Institute

\section{Source}

National Cancer Institute. Appendiceal Carcinoma pT 4a TNM Finding v8. NCI Thesaurus. Code C134101.

Appendiceal carcinoma with tumor invading through the visceral peritoneum, including the acellular mucin or mucinous epithelium involving the serosa of the appendix or serosa of the mesoappendix. (from AJCC 8th Ed.) 